\title{
FORCE MEASUREMENT OF HAND AND FINGERS
}

\author{
Károly János Bretz ${ }^{1}$, Ákos Jobbágy ${ }^{1}$, Károly Bretz ${ }^{2}$ \\ ${ }^{1}$ Budapest University of Technology and Economics \\ ${ }^{2}$ Semmelweis University TF \\ bretzkarl@hotmail.com
}

\begin{abstract}
Objective: To determine forces of hand and fingers in model situations.
\end{abstract}

Methods: Subjects were 16 university students (males). Dyna-8 force measuring system was used, which is equipped with transducers making the measurement of handgrip strength and forces of fingers possible. The maximum force value is displayed digitally and simultaneously, the complete force diagram is shown on the computer monitor.

Results: Right and left hand strengths and forces of all fingers were recorded, and descriptive statistics, correlation analysis, and t-test were executed. Forces of right and left hand strengths correlate, but differ significantly when their means are compared. Forces of the same fingers on the right and left hand correlate significantly with the exception of the middle and index fingers.

Conclusion: Hand and finger force data are used in numerous sport types, industrial design, ergonomics, and rehabilitation.

Keywords: dynamometers; hand strength; finger force; ergonomics; rehabilitation control

\section{Introduction}

The application field of hand and finger force measurements is related to the industrial design of hand tools, workstations, vehicles, and human-machine interfaces requiring force while manipulating these means (Figure 1). Taking into account the data of the above-mentioned forces and the construction requirements, one can improve comfort and minimize hand injuries (Valero-Cuevas, 2000). Development of hand and finger force is worthy of attention in several types of sport, e.g., judo, wrestling, weightlifting, hammer throw, discus throwing, tennis, gymnastics, rock climbing, etc. Devices and computerized measuring systems are in the available literature, which are capable of recording isomet-

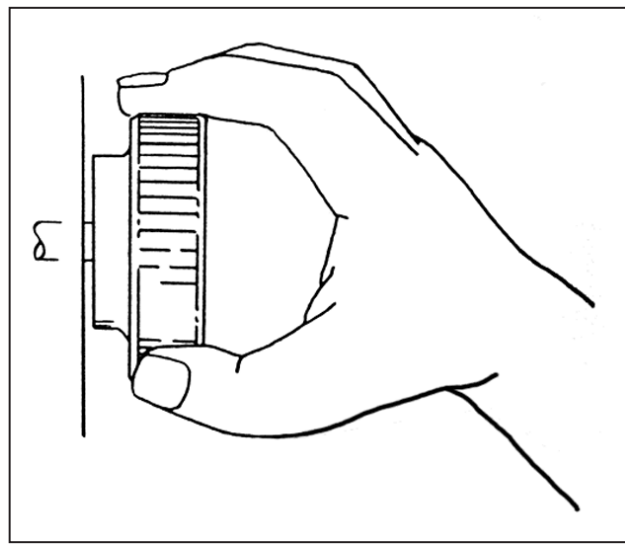

Figure 1. Setting a turning button

ric, isotonic, and isokinetic forces. (Yokogawa, Hara, 2002, Zatsiorsky, 2002, Kiung Ki Uk et al., 2004) 
The purpose of the present study was to focus on our special measuring system and typical data regarding whole-hand grasp forces and finger pinch exertions.

\section{Methods}

Sixteen healthy subjects, university students (males), consented to participate in the study; aged: $21.2 \pm 1.48$ years, body height: 182.7 $\pm 9.19 \mathrm{~cm}$, body mass: $77.85 \pm 10.03 \mathrm{~kg}$.

A Dyna-8 type general purpose, portable measuring system was developed, allowing the user to selectively collect numeric data and diagrams on hand and finger forces. The system can be connected to a host PC via USB to serial converter.

During the recording the maximum force value is fixed by a microcontroller and shown digitally on the electronic unit display. The force diagram is displayed simultaneously on the computer monitor (Bretz KJ et al., 2006).

Range of finger force measurement: $2-120 \mathrm{~N}$ Range of all-purpose force measurement:

Linearity:

Hysteresis:

Sampling frequency: $\pm 1.5 \%$ $\pm 1.5 \%$

Dimensions:

Hand grip adapter:

Finger force adapter:

Electronic unit:

$300 \mathrm{~Hz}$

Complete mass:

$250 \times 150 \times 30 \mathrm{~mm}$

$\varnothing 22 \times 100 \mathrm{~mm}$ $200 \times 150 \times 80 \mathrm{~mm}$

Battery:

Power supply with mains adapter:

$4.2 \mathrm{~kg}$

$9 \mathrm{~V}$

$9 \mathrm{~V}$

\section{Performance of the measuring system}

Force diagram recording time with PC: $240 \mathrm{~s}$.

Manual scanning function.

Zoom function.

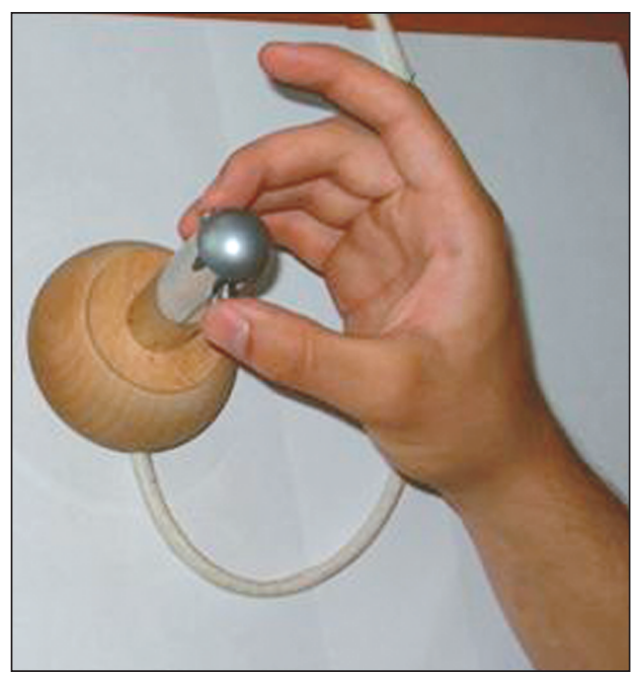

Figure 2. The selective finger force measurement. Middle finger-thumb. (At right)

Automatic maximum force value with time and slope value displaying.

Storage function, data bank.

Text file produced for Excel.

During the finger force measurement, the lower arm was on the table (Figure 2). In this lower arm position the subjects pressed their fingers on the flat surfaces of the two screws on the adapter- one screw with the thumb and the opposite screw with any other finger (Figure 2 and 3). During the measurement the subjects shaped a circle with their fingers in a horizontal plane.

They could easily do it in the given situation, since the height of the adapter of the two pressbuttons was about $100 \mathrm{~mm}$, which ensured a comfortable handling of the instrument. A visual feedback was also applied during the experiment. The subjects could see the formation of the force diagram on the computer screen simultaneously with the force exertion.

The next task was the measurement of the hand grasping force. 


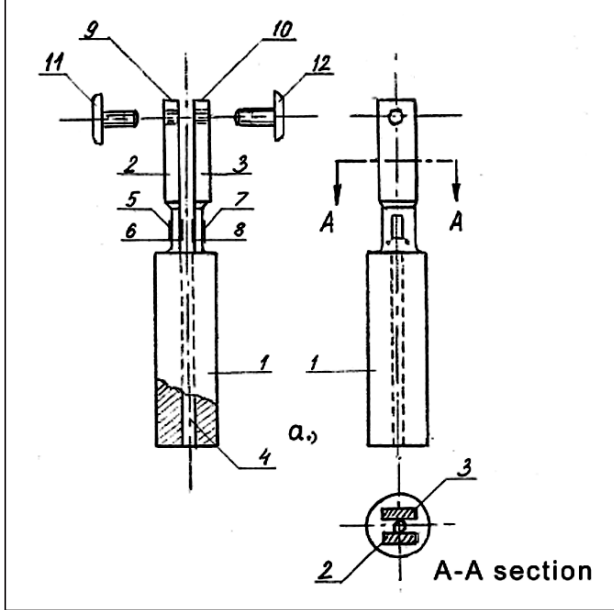

Figure 3. The fork-shaped measuring element built in the adapter (Figure 2 and 4)

Figure 3 illustrates the lateral view, front-view, and cross-sectional view of the fork-shaped measuring element (1), built in the adapter (Figure 4). The strain gauges $(5,6,7,8)$ connected in a Wheatstone bridge, are stuck to the measuring plates $(2,3)$, in which screws

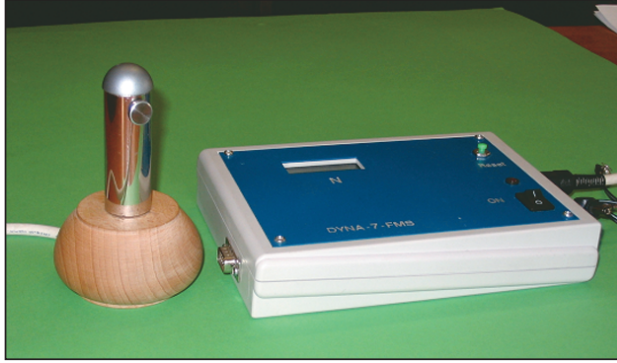

Figure 4. The finger force sensor adapter and the electronic unit

$(11,12)$ produced with pressure surface are fixed. During measurement, as shown in Figure 2, the middle finger and the thumb grasp and press the screws on the pressure surfaces.

\section{Results}

Table 1 summarizes the hand and finger force values (16 male subjects). Tables 2, 3 and 4 show the correlations between maximum finger forces.

\begin{tabular}{|c|c|c|c|c|c|c|}
\hline \multicolumn{7}{|c|}{ Force measurement, right hand $(\mathrm{N})$} \\
\hline & Hand & Little finger & Ring finger & Middle finger & Index finger & Thumb \\
\hline Average & 551.2 & 30.8 & 37.9 & 55.1 & 56.7 & 107.7 \\
\hline St. deviation & 74.5 & 11.57 & 10.08 & 17.3 & 12.62 & 30.68 \\
\hline \multicolumn{7}{|c|}{ Force measurement, left hand $(\mathrm{N})$} \\
\hline & Hand & Little finger & Ring finger & Middle finger & Index finger & Thumb \\
\hline Average & 505.2 & 28.4 & 37 & 53.7 & 60.4 & 109.5 \\
\hline St. deviation & 112.7 & 10.26 & 11.26 & 12.04 & 14.6 & 28.9 \\
\hline
\end{tabular}

Table 1. Results of force measurements: averages and standard deviations

\begin{tabular}{|c|c|c|c|c|c|c|}
\hline \multicolumn{2}{|c|}{$\begin{array}{c}\text { Correlation coefficients } \\
\text { \& significances }\end{array}$} & $\begin{array}{c}\text { Little finger } \\
\text { Right }\end{array}$ & $\begin{array}{c}\text { Ring finger } \\
\text { Right }\end{array}$ & $\begin{array}{l}\text { Middle finger } \\
\text { Right }\end{array}$ & $\begin{array}{c}\text { Index finger } \\
\text { Right }\end{array}$ & $\begin{array}{c}\text { Thumb } \\
\text { Right }\end{array}$ \\
\hline Little finger & (Right) & 1 & & & & \\
\hline Ring finger & (Right) & $\begin{array}{l}0.790^{* *} \\
\mathrm{p}<0.000\end{array}$ & 1 & & & \\
\hline Middle finger & (Right) & $\begin{array}{l}0.647^{* *} \\
\mathrm{p}<0.007\end{array}$ & $\begin{array}{l}0.744^{* *} \\
\mathrm{p}<0.001\end{array}$ & 1 & & \\
\hline Index finger & (Right) & $\begin{array}{c}0.349 \\
\mathrm{p}<0.185\end{array}$ & $\begin{array}{c}0.564^{*} \\
\mathrm{p}<0.023\end{array}$ & $\begin{array}{c}0.242 \\
\mathrm{p}<0.366\end{array}$ & 1 & \\
\hline Thumb & (Right) & $\begin{array}{c}-0.454 \\
\mathrm{p}<0.077\end{array}$ & $\begin{array}{c}-0.253 \\
\mathrm{p}<0.343\end{array}$ & $\begin{array}{c}-0.079 \\
\mathrm{p}<0.772\end{array}$ & $\begin{array}{c}-0.371 \\
\mathrm{p}<0.158\end{array}$ & 1 \\
\hline
\end{tabular}

Table 2. Correlations between right hand finger forces 


\begin{tabular}{|c|c|c|c|c|c|c|}
\hline \multicolumn{2}{|c|}{$\begin{array}{c}\text { Correlation coefficients } \\
\text { \& significances }\end{array}$} & $\begin{array}{l}\text { Little finger } \\
\text { Left }\end{array}$ & $\begin{array}{c}\text { Ring finger } \\
\text { Left }\end{array}$ & $\begin{array}{l}\text { Middle finger } \\
\text { Left }\end{array}$ & $\begin{array}{l}\text { Index finger } \\
\text { Left }\end{array}$ & $\begin{array}{c}\text { Thumb } \\
\text { Left }\end{array}$ \\
\hline Little finger & (Left) & 1 & & & & \\
\hline Ring finger & (Left) & $\begin{array}{c}0.610^{*} \\
\mathrm{p}<0.012\end{array}$ & 1 & & & \\
\hline Middle finger & (Left) & $\begin{array}{c}0.439 \\
\mathrm{p}<0.089\end{array}$ & $\begin{array}{c}0.661^{*} \\
\mathrm{p}<0.005\end{array}$ & 1 & & \\
\hline Index finger & (Left) & $\begin{array}{c}0.446 \\
\mathrm{p}<0.084\end{array}$ & $\begin{array}{c}0.537^{*} \\
\mathrm{p}<0.032\end{array}$ & $\begin{array}{c}0.642^{* *} \\
\mathrm{p}<0.007\end{array}$ & 1 & \\
\hline Thumb & (Left) & $\begin{array}{c}-0.228 \\
\mathrm{p}<0.396\end{array}$ & $\begin{array}{c}0.120 \\
\mathrm{p}<0.659\end{array}$ & $\begin{array}{c}0.063 \\
\mathrm{p}<0.816\end{array}$ & $\begin{array}{c}0.394 \\
\mathrm{p}<0.131\end{array}$ & 1 \\
\hline
\end{tabular}

Table 3. Correlations between the left hand finger forces

\begin{tabular}{|c|c|c|c|c|c|c|}
\hline \multicolumn{2}{|c|}{$\begin{array}{l}\text { Correlation coefficients } \\
\text { \& significances }\end{array}$} & $\begin{array}{c}\text { Little finger } \\
\text { Left }\end{array}$ & $\begin{array}{c}\text { Ring finger } \\
\text { Left }\end{array}$ & $\begin{array}{l}\text { Middle finger } \\
\text { Left }\end{array}$ & $\begin{array}{c}\text { Index finger } \\
\text { Left }\end{array}$ & $\begin{array}{l}\text { Thumb } \\
\text { Left }\end{array}$ \\
\hline Little finger & (Right) & $\begin{array}{l}0.719^{* *} \\
\mathrm{p}<0.002\end{array}$ & $\begin{array}{c}0.565^{*} \\
\mathrm{p}<0.023\end{array}$ & $\begin{array}{c}0.408 \\
\mathrm{p}<0.117\end{array}$ & $\begin{array}{c}0.453 \\
\mathrm{p}<0.078\end{array}$ & $\begin{array}{c}-0.151 \\
\mathrm{p}<0.591\end{array}$ \\
\hline Ring finger & (Right) & $\begin{array}{l}0.665^{* *} \\
\mathrm{p}<0.005\end{array}$ & $\begin{array}{l}0.626^{* *} \\
\mathrm{p}<0.01\end{array}$ & $\begin{array}{c}0.572 * \\
\mathrm{p}<0.021\end{array}$ & $\begin{array}{c}0.502^{*} \\
\mathrm{p}<0.047\end{array}$ & $\begin{array}{c}0.028 \\
\mathrm{p}<0.919\end{array}$ \\
\hline Middle finger & (Right) & $\begin{array}{c}0.341 \\
\mathrm{p}<0.196\end{array}$ & $\begin{array}{c}0.427 \\
\mathrm{p}<0.099\end{array}$ & $\begin{array}{c}0.469 \\
\mathrm{p}<0.068\end{array}$ & $\begin{array}{c}0.427 \\
\mathrm{p}<0.099\end{array}$ & $\begin{array}{c}-0.098 \\
p<0.717\end{array}$ \\
\hline Index finger & (Right) & $\begin{array}{c}0.409 \\
\mathrm{p}<0.116\end{array}$ & $\begin{array}{c}0.32 \\
\mathrm{p}<0.227\end{array}$ & $\begin{array}{c}0.601^{*} \\
\mathrm{p}<0.014\end{array}$ & $\begin{array}{c}0.393 \\
\mathrm{p}<0.132\end{array}$ & $\begin{array}{c}-0.254 \\
\mathrm{p}<0.342\end{array}$ \\
\hline Thumb & (Right) & $\begin{array}{l}-0.695 * * \\
\mathrm{p}<0.003\end{array}$ & $\begin{array}{l}-0.507^{*} \\
\mathrm{p}<0.045\end{array}$ & $\begin{array}{c}-0.465 \\
\mathrm{p}<0.069\end{array}$ & $\begin{array}{c}-0.197 \\
p<0.465\end{array}$ & $\begin{array}{c}0.506^{*} \\
\mathrm{p}<0.045\end{array}$ \\
\hline
\end{tabular}

Table 4. Correlations between the right and left finger forces

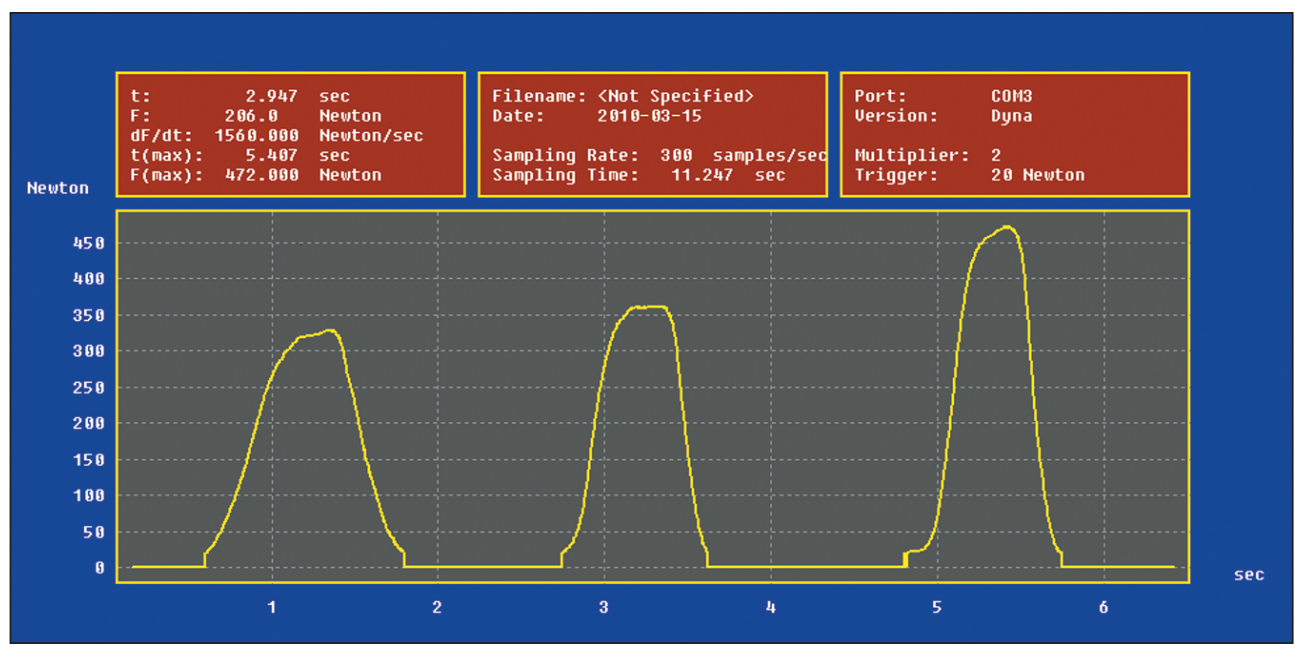

Figure 6. Diagram of hand grasping forces.

The following data are displayed: forces related to time elapsed; slope of the diagrams ( $\mathrm{dF} / \mathrm{dt}$ ) at any time during measurement; maximum force and the moment when it occurred; sampling rate; measuring time; zoomed part; (adjustable) trigger level $(20 \mathrm{~N})$, etc. 


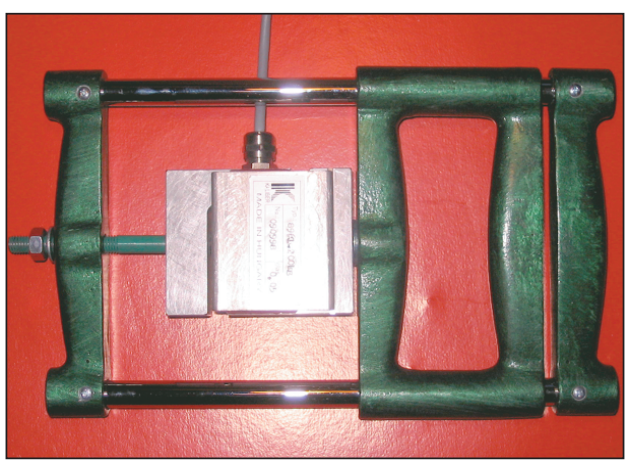

Figure 5. Hand grip adapter with force sensor

\section{Discussion}

The first goal of this study was to describe hand and finger force capabilities in relation to various couplings with handles and levers. The knowledge of grasping force makes it possible to create an estimation of the general neuromuscular power of the subject. Body dimensions correlate with maximum hand force (Roman-Liu et al., 2004).

Many researchers have already dealt with the measurement of finger forces. They have developed various methods in order to do this (Yokogawa and Hara, 2002). In some cases they applied the kind of sensors which simultaneously measured the exertions between the thumb and the other four fingers. The transducers are up-to-date, almost all of them are accurate and linear (Zatsiorsky, 2002, Gorniak et al., 2007).

In earlier solutions, there are four sensors opposing the thumb, but in some cases, none of these is opposite the sensor of the thumb. The axis of this sensor is coincident with the vector of the pressure force of the thumb, and is projected to the midpoint of the distance between the sensors of the middle finger and the ring finger on the opposite side of the sensor equipment. In the case of a fixed transducer this fact would not cause any problems. Using an elegant solution, the sensors were built in a table (Latash et al., 2007). If the reaction force against the other four fingers occurs due to the press of the thumb, and the sensor equipment is not fixed, then really only the (maximum) force of the thumb can be measured. The total force exerted by the four fingers could be greater than that of the thumb. As a consequence, with this method the maximal force exertion of the thumb, as well as the force distribution between the other fingers could be measured.

In order to determine the forces and torques of the other four fingers and their maximal values, the vector of the pressing force of the thumb has to coincide with the vector of the pressing force of one of the other fingers. While pinching with the thumb and any other finger, the force of the index, middle, ring, or little finger can be measured since the thumb is able to exert a greater force than any other finger due to its muscular and anatomical structure.

Bearing in mind the above mentioned conditions, the force measuring adapter was constructed in a way that it makes the selective measuring of the forces of fingers possible. According to this design, the uniaxial arrangement satisfies the original aim (Bretz et al., 2006).

Hand and finger force data can be used in numerous types of sport, industrial design, ergonomics, and rehabilitation. 


\section{REFERENCES}

1. Bretz KJ, Jobbágy Á, Bretz K. (2006) Equipment for investigation of hand and finger tremor and finger forces. Utility model, Hungarian Patent Office. Reg. No: 3 305. 1-11 p. (in Hungarian)

2. Gorniak SL, Zatsiorsky VM, Latash ML. (2007) Hierarchies of synergies: an example of two-hand multi-finger tasks. Exp. Brain. Res., 179:167-180.

3. Kiung KU, Kwon D-S, Choi HJ et al. (2004) Mouse interface device transmitting reaction force to user's arm and finger Patent No.: JP2004220593 and US2004140953, and DE102004001870.

4. Lee $M$, Chien $M$ (TW) (2004) "Finger gripping force measuring or testing device" Patent No.: US6725728 1-3.p.

5. Roman-Liu D, Tokarski T, Wojcik K. (2004) Quantitative assessment of upper limb muscle fatigue depending on the conditions of repetitive task load. J. of Electromyography \& Kinesiology, 14(6):671-682.

\section{Károly Bretz}

Semmelweis University TF

Dept. of Biomechanics

H-1123 Budapest, Alkotás u. 44.
6. Valero-Cuevas FJ. (2000) Predictive modulation of muscle coordination pattern magnitude scales fingertip force magnitude over the voluntary range. The Journal of Neurophysiology, 83(3): 1469-1479.

7. Yokogawa R, Hara K. (2002) Measurement of distribution of maximum index-fingertip force in all directions at fingertip in flexion/extension plane. Journal of Biomechanical Engineering, 124:(3) 302-307.

8. Zatsiorsky VM (2002) Kinetics of human motion, ISBN 0-7360-3778-0. Human Kinetics, Champaign, IL USA.

9. Zhang W, Zatsiorsky VM, Latash ML. (2007) Finger synergies during multi-finger cyclic production of moment of force. Exp. Brain. Res., 177: 243-254. 